Article

\title{
Accuracy of Deformation Rates from Campaign GPS Surveys Considering Extended Observation Session and Antenna Set-Up Errors
}

\author{
Yener Turen ${ }^{1}\left(\mathbb{D}\right.$ and D. Ugur Sanli ${ }^{2, *}$ \\ 1 Map and Cadaster Program, Vocational College of Technical Sciences, Trakya University, \\ 22100 Edirne, Turkey; yenerturen@trakya.edu.tr \\ 2 Department of Geomatic Engineering, Faculty of Civil Engineering, Yildiz Technical University, \\ 34220 Istanbul, Turkey \\ * $\quad$ Correspondence: usanli@yildiz.edu.tr; Tel.: +90-212-383-5281 or +90-212-383-5270
}

Received: 30 April 2019; Accepted: 22 May 2019; Published: 23 May 2019

\begin{abstract}
GPS campaign measurements are still in use in the monitoring of ground deformation. Campaign measurements are frequently referred to because installing permanent stations are costly, and they cannot be installed at the desired density. Using the data from the International Global Navigation Satellite Systems (GNSS) Service (IGS) permanent GPS stations, the duration, sampling interval, etc. of the campaign measurements can be simulated. Thus, the contribution of the campaign data to the monitoring of the ground deformation can be evaluated. In this study, we carried out an experiment with the aim of determining the deformation of tectonic plates at the selected IGS stations more accurately considering by extending the observation duration to a full $24 \mathrm{~h}$ length. We also made an attempt to take into consideration the antenna set up errors developing a scenario referring to the information available in the literature. We have decimated the continuous data of 40 globally scattered IGS stations into monthly intervals between 2012 and 2016 and estimated the deformation rates at the IGS stations from a continuous time series of four years. The continuous time series solutions for those stations were produced by the Jet Propulsion Laboratory (JPL), NASA. We compare velocities (i.e., the deformation rates) determined from GPS campaigns (in which the sampling was performed monthly and four-monthly) with those of the continuous data. The major conclusion of this study is that the vertical velocity estimation accuracy of the GPS campaign measurements had been improved by about $85 \%$ by extending the session duration to $24 \mathrm{~h}$. The repetition interval of GPS campaign measurements as per one observation every four months produced only slightly coarser accuracy (i.e., on the average $8 \%$ poorer) than those of the measurements repeated once every month.
\end{abstract}

Keywords: GPS time series; IGS network; Velocity estimation; Fourier analysis; GPS campaigns; ground deformation; tectonic motion

\section{Introduction}

Repeated surveys (i.e., GPS campaigns) with the repetition rate of several consecutive days per year and with session durations of 8-24 $\mathrm{h}$ were frequently referred to in the history of GPS positioning [1-3]. GPS short occupations (i.e., $<24 \mathrm{~h}$ ) are biased because of the severe atmospheric conditions on the GPS signal, multipath environment, bad satellite-receiver geometry, etc. [4]. One needs to use complete $24 \mathrm{~h}$ data to overcome the above disturbances. Furthermore site occupations should last several consecutive days to eliminate bad solutions from the available results. All possible irregularities occurring with the above mentioned reasons can only be sampled in one complete day. The next day, the same satellite constellation and hence the same observation pattern repeats four minutes earlier. Positioning 
from shorter occupations generally results in coarser accuracy [5,6]. There were several reasons GPS campaign measurements must be carried out with short site occupations. First, field operators wanted to take advantage of the day light. Second, it was secure to employ receivers before sunset, and field operators wanted to avoid unfavorable overnight conditions. Then continuously operating reference system (CORS) networks started to be used however they were not installed as dense as desired in all types of deformation monitoring works. Obviously, CORS were costly and thus were not adopted by many researchers in all kind of deformation monitoring tasks.

GPS campaigns were used in sea level experiments [7], determination of geopotential values [8], monitoring of regional tectonics [9-11], natural hazard monitoring such as landslides [12,13], and others [14-16]. In each of those experiments the goal was the same; estimating the deformation rate. CORS then became widespread, especially in the tectonically active areas. The GPS time series were accumulated and deformation rates obtained from those time series were assessed. The character of the seasonal signal on the vertical component was determined [17]. The optimum length of time series in obtaining true velocities (i.e., deformation rates) was experimentally determined. The noise characteristics of the time series and the effect on the estimated deformation were studied [18-20]. At times, GPS experiments were carried out in which the site occupation was performed in a rate of once per year with $8-10 \mathrm{~h}$ of the observation session. This was the worst case scenario for repeated GPS surveys because the researcher was not able to eliminate bad observations from a set of site occupations. In many studies, the velocity estimated from GPS campaigns was assumed to be equivalent to the velocity derived from continuous GPS. This assumption could be true only if a proper processing strategy (e.g., short baseline lengths to reference stations processed by commercial software) was adopted [21]. According to the theory of Blewitt and Lavallee [17], there was an annually repeating significant seasonal motion on the vertical GPS component, and the GPS data sampled at the rate of once per year would not reveal that effect on the positioning results. Akarsu, et al. [22] noticed this and estimated the velocity of tectonic plates (i.e., the horizontal motion) using campaign GPS measurements from the data sampled once per year with the observation session duration of $8-12 \mathrm{~h}$. The sampling rate for the vertical component was increased to once per month with the same session duration to reveal the effect of sinusoidal motion. The study mainly targeted to criticize the work performed with site occupations less than $24 \mathrm{~h}$ and repeated less frequently. They compared the velocity estimated from the GPS campaigns based on short occupations with that of GPS campaigns using the full $24 \mathrm{~h}$ observation period. Based on the analyses performed with $95 \%$ reliability, only $30-40 \%$ of horizontal velocities from 8-12 h GPS campaigns agreed with the velocities derived from $24 \mathrm{~h}$ sessions. On the other hand none of the vertical velocities derived from 8-12 h campaigns agreed with $24 \mathrm{~h}$ sessions. Duman and Sanli [23] applied a refinement procedure to Akarsu, Sanli and Arslan [22] to improve the success of the velocities derived from GPS campaigns. They eliminated the noisy time series obtained in the years 1992-1999 from the generation of campaign measurements, chose GPS days from quieter ionospheric conditions with a kappa index $<4$, used data from three consecutive days, reprocessed Jet Propulsion Laboratory (JPL) orbits and clocks were used in the analysis, and the east component was improved with the new single receiver ambiguity resolution algorithm of GIPSY/OASIS II. They managed to improve the horizontal velocity estimation success on average by up to $50 \%$ and $70 \%$ for $8 \mathrm{~h}$ and $12 \mathrm{~h}$ sessions, respectively. The success of the vertical component was only improved by $10 \%$ on average. The fractions recommended by the above studies are not significant. Geng, et al. [24] showed that GIPSY's PPP-Ambiguity Resolution can further be improved if the satellite clock can be re-estimated as well.

Akarsu, Sanli and Arslan [22] and Duman and Sanli [23] used the full 15-year span of the available GPS time series. Furthermore, they used the International GNSS Service (IGS) data to sample the campaign measurements at once per month. Although the above efforts were useful to understand the nature of campaign GPS solutions, they were not indeed applicable for practical situations. Considering this and taking into account weak points, such as observation session length, we set up a different experiment. First of all, we extend the observation session duration of campaign measurements to 
$24 \mathrm{~h}$. We use GNSS time series as short as four years in which the ground deformation has been found to be detectable $[17,25]$. The data is sampled once every four months in a year considering practical needs. We also tested the sampling once per month as done in Akarsu, Sanli and Arslan [22] to quantify what we lose by repeating the surveys every four months. Furthermore, we account for the antenna set-up errors by a scenario based on the studies of Dixon [26] and Gili et al. [27]. Monthly samples were generated by decimating the continuous time series of the Jet Propulsion Laboratory (JPL). Data was sampled from a globally distributed network of GNSS stations selected from the archives of the International GNSS service (IGS). For each station of the IGS network, first a velocity was estimated from the generated campaign data and then from the continuous GNSS data. We then tested the significance of the velocity derived from monthly repeated GPS surveys against the velocity obtained from the continuous data.

\section{Analysis of the GPS Data}

Forty homogenously distributed IGS points and their four-year solution time series provided by the Jet Propulsion Laboratory (JPL) for the period 2012 through 2016 were used (Figure 1). For this, we referred to the National Aeronautics and Space Administration (NASA)-JPL official website (http://sideshow.jpl.nasa.gov/post/series). Position time series for each IGS station concerning local topocentric coordinates north, east, and up (n, e, and $\mathrm{u}$ ) and accompanying standard errors were downloaded.

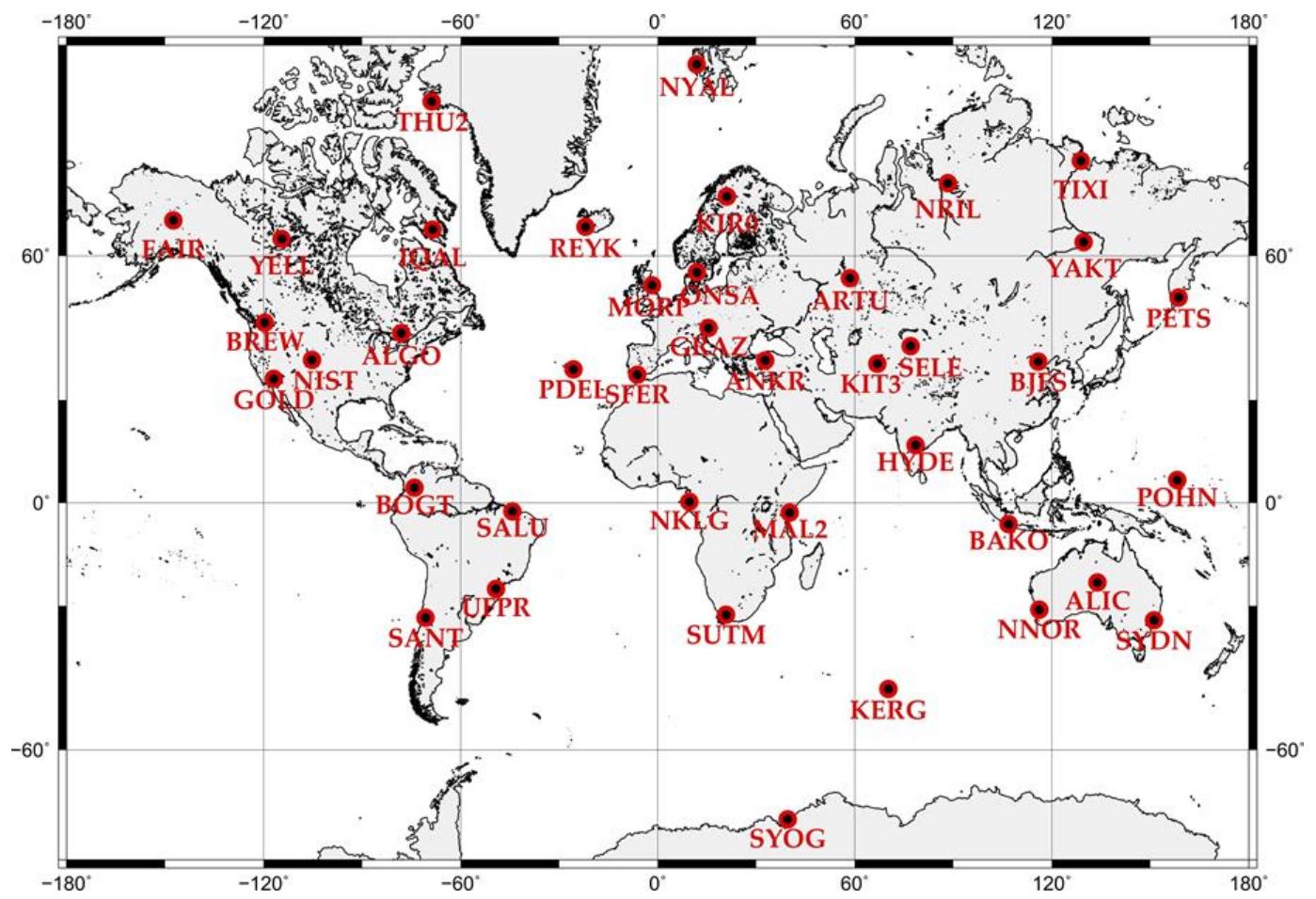

Figure 1. Locations of the International GNSS Service (IGS) stations used in this study.

First, the JPL continuous time series constituting daily position estimates were decimated into monthly sampled GPS campaign time series by picking only one position estimate (i.e., day fifteen here) from each month of the year. In practice, this means that the field operator occupies the geodetic survey point with a GPS receiver every month in a year. This might be considered an ideal survey procedure, which is much denser than the one measurement per year. Obviously this would be much more cumbersome than the traditional field work in which the geodetic mark is visited for a couple of consecutive days each year [1]. Considering this we worked on an alternative survey procedure in which the sampling is made selecting one position estimate (i.e., derived from full 24 h) every 
four months. This is surely superior to the sampling; one measurement per year with $8-10 \mathrm{~h}$ of observation session.

Secondly, we estimated the deformation rate from a four-year continuous JPL time series. Blewitt and Lavallee [17] and Wang, Turco, Soler, Kearns and Welch [25] assess the minimum span of continuous GPS time series for the appropriate determination of the deformation rate. They recommend a minimum span for deformation monitoring of between 2.5 and 4.5 years. Figure 2 shows GOLD continuous, monthly, and four-monthly decimated campaign time series.

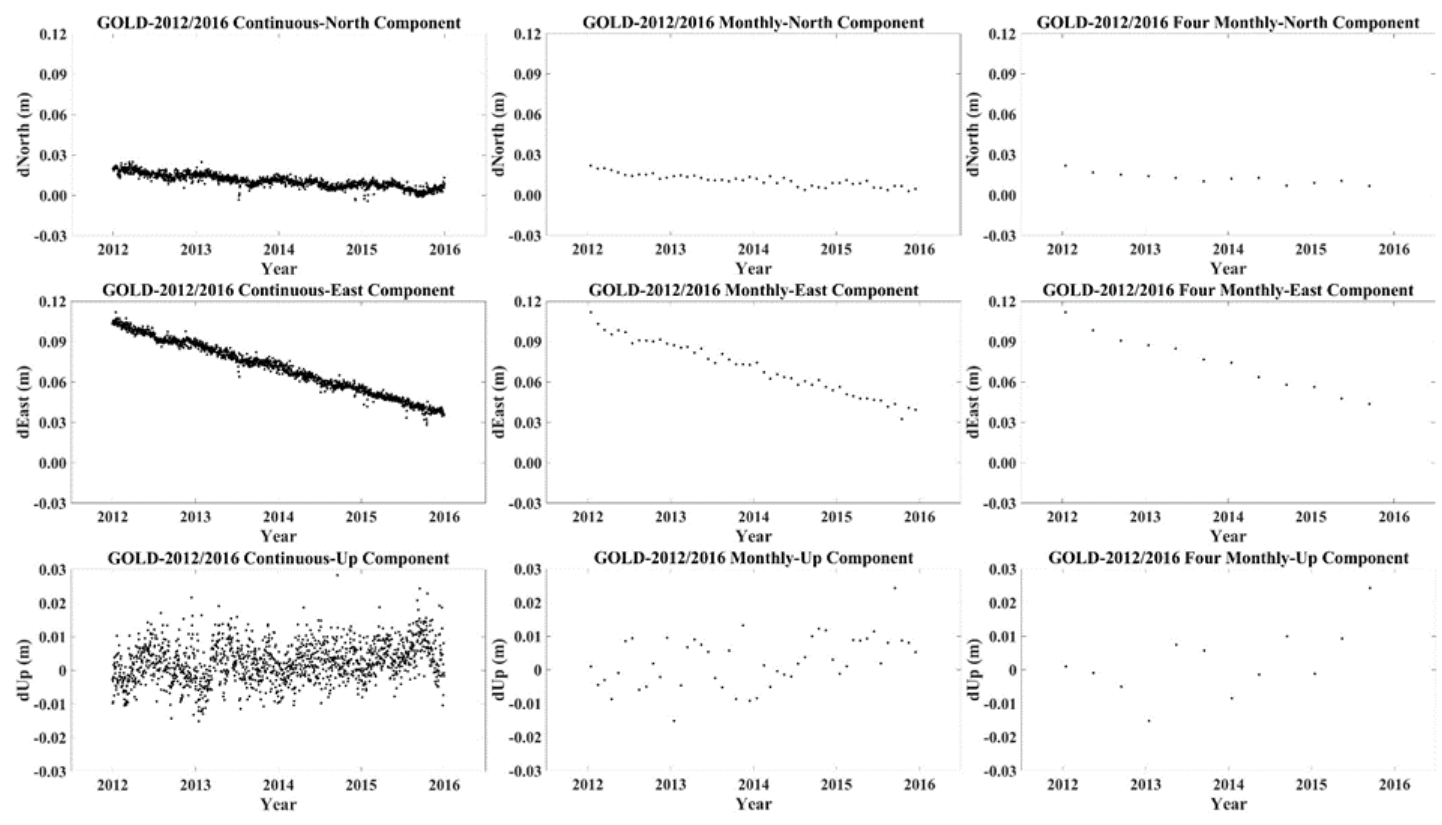

Figure 2. Continuous, monthly, and four-monthly time series of the IGS station GOLD from 2012 to 2016.

Furthermore, to take into account the antenna set up error, we added some biases to the coordinate components north, east, and up. As noted earlier on, we generated synthetic GPS campaigns using the data of IGS continuously operating stations where the antennas are usually on top of concrete pillars and their position does not change over time. However, campaign GPS measurements are usually collected by mounting the GPS antenna on top of a tripod while visiting the survey sites. This would create an error due to possible improper centering and incorrect measurement of the antenna height. Considering the antenna set up error would be randomly distributed over a long time period, it was generated synthetically as a random noise produced from a MATLAB routine. On the magnitude of the bias we referred to Dixon [26] and Gili, Corominas and Rius [27] who assesses the antenna set-up errors. The bias is noted to be 1-3 mm from the setup of tripod mounted GPS antennas using optical plummets. Therefore we generated white noise with the standard deviation of $3 \mathrm{~mm}$. The best way to assess this would be taking campaign measurements near to $(<10 \mathrm{~m})$ continuous stations however we would not be able to produce our results globally.

\section{Velocity Estimation Using Least Squares Analysis and Statistical Testing}

Annual and semi-annual components were included in the least squares estimation as the time dependent coefficients, and the unknown parameters $\mathrm{a}, \mathrm{b}, \mathrm{c}_{1}, \mathrm{c}_{2}, \mathrm{~d}_{1}, \mathrm{~d}_{2}$, and $x_{\text {off }}$ were estimated using the regression equation:

$$
\mathrm{y}(\mathrm{t})=\mathrm{a}+\mathrm{b} \cdot \mathrm{t}+\mathrm{c}_{1} \cdot \sin \left(\frac{2 \pi t}{T_{1}}\right)+\mathrm{d}_{1} \cdot \cos \left(\frac{2 \pi t}{T_{1}}\right)+\mathrm{c}_{2} \cdot \sin \left(\frac{2 \pi \mathrm{t}}{T_{2}}\right)+\mathrm{d}_{2} \cdot \cos \left(\frac{2 \pi t}{T_{2}}\right)+o \cdot x_{o f f}+v(t)
$$


where $a$ is the intercept, $b$ is the velocity, $c_{1}$ and $d_{1}$ are periodical constituents for the annual term whereas $c_{2}$ and $d_{2}$ are periodical constituents for the semi-annual term. In addition, $T_{1}$ and $T_{2}$ are periods of annual and semi-annual periodic components, which were taken to be 1.0 cycle and 0.5 cycles, respectively. $x_{o f f}$ is an offset term and $v(t)$ represents residuals. Bogusz and Klos [20] performed a detailed study on the IGS continuous time series, where a wide spectrum of periodic components were investigated. However, here only the major annual and semi-annual periodicities of the seasonal variation were included in the Least Squares Estimation (LSE) analysis for simplicity. Similarly, we did not choose our stations from places in which the time series contain transients. This would have requested detailed modeling and station specific care. The reader should refer to Ji and Herring [28,29] for transients in time series.

The velocity b in Equation (1) was estimated for all; monthly, four-monthly, and continuous data. Figures 3 and 4 show the horizontal and vertical velocity fields of continuous and monthly sampled data.

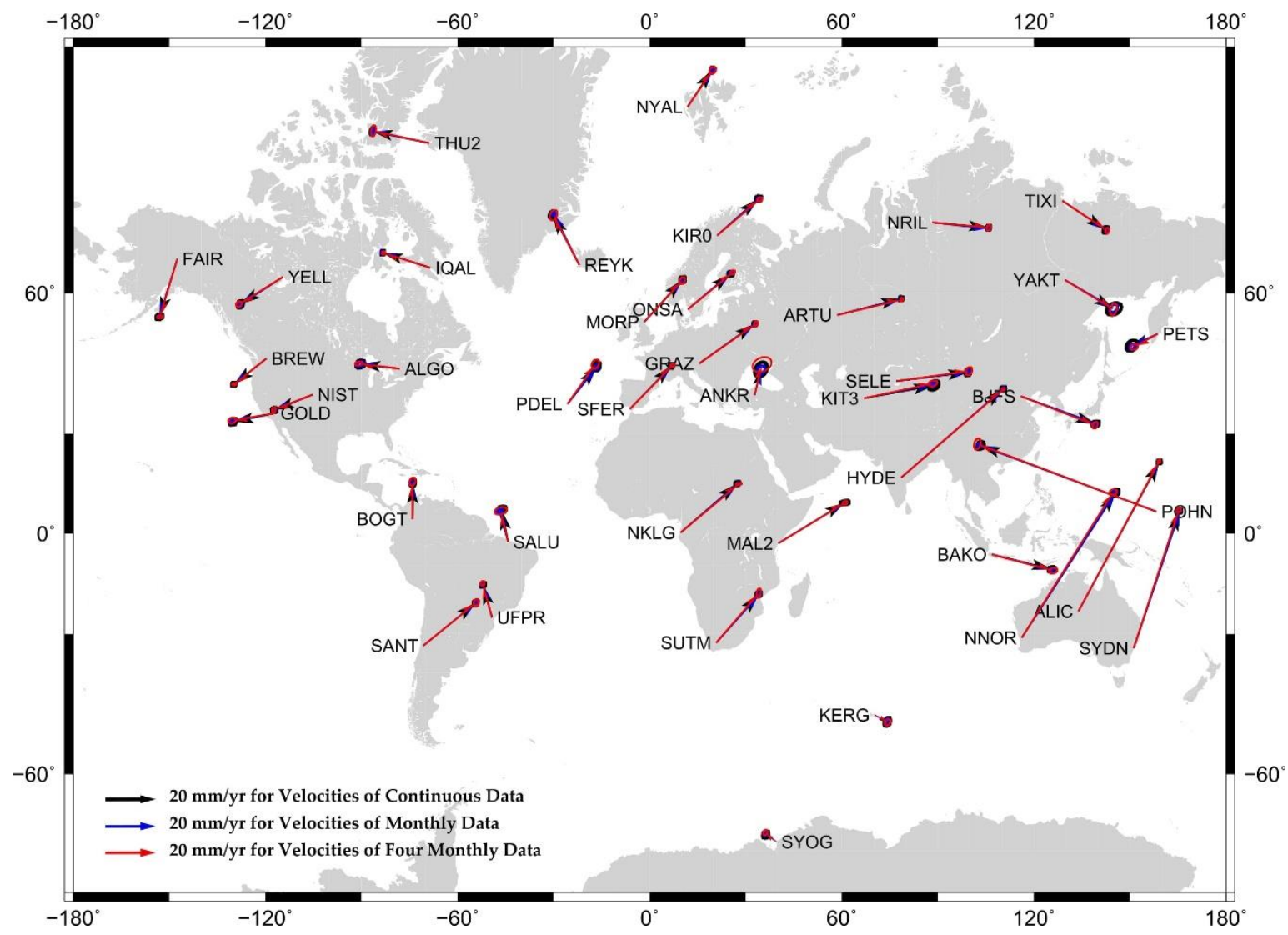

Figure 3. Horizontal velocities of continuous, monthly, and four monthly data with their standard errors. 


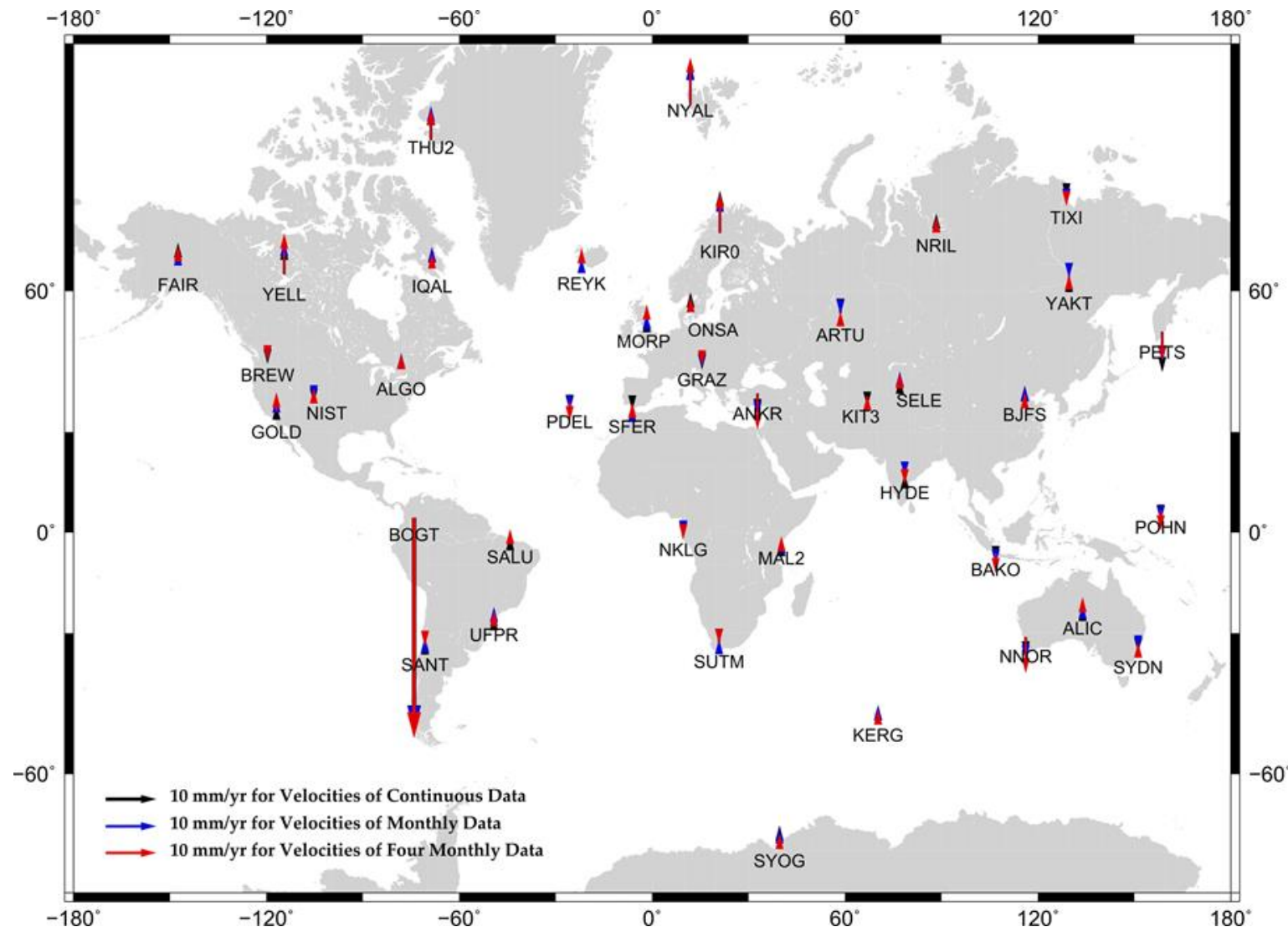

Figure 4. Vertical velocities of continuous, monthly, and four monthly data with their standard errors.

In addition, the other unknown parameters and their associated standard errors were also computed for $\mathrm{n}, \mathrm{e}$, and $\mathrm{u}$ components. Then we applied a Student's t-test as to whether the velocities from the monthly (or four-monthly) solutions differ significantly from those of the daily solutions. The formulation and the notation for the t-test from a multi-regression analysis is given in Table 1 .

Table 1. Notation and formulation for the Student's t-test from multi-regression analysis.

\begin{tabular}{cc}
\hline Test Statistic & Critical Region \\
\hline$T=\frac{b_{m}-b_{d}}{\mathrm{~s} \cdot \sqrt{q_{i} q_{i}}}$ & $T<-1.96$ or $T>1.96$
\end{tabular}

$b_{d}=$ daily velocity; $b_{m}=\overline{=m o n t h l y ~(o r ~ f o u r-m o n t h l y) ~ v e l o c i t y ; ~} s=$ unit variance from LSE; $q_{i}=$ element of the cofactor matrix.

The zero hypothesis was set to be $H_{0}: b_{m}=b_{d}$ and the alternative hypothesis $H_{A}: b_{m} \neq b_{d}$. If, for a two-sided test, $\mathrm{T}$ exceeds \pm 1.96 with $\alpha=0.05$ then $\mathrm{H}_{0}$ is rejected. In other words, the velocity estimated from monthly (or four-monthly) GPS campaigns is significantly different than that of the continuous GPS.

In the Figures 3 and 4, antenna set-up errors were not yet imposed on the velocities. Obviously the estimated deformation rate could be biased due to this. Horizontal velocities were given with error ellipses having a 95\% confidence level. The ellipse unit was $10 \mathrm{~mm}$ in the figure. Note that velocities from the continuous, monthly, and four-monthly time series were pretty much comparable (i.e., the direction and magnitude of black, blue, and red arrows coincided well). The detailed results of the statistical hypothesis testing, which are not obvious in Figures 3 and 4 are given in Figure 5. It is seen from the figure that a tremendous amount of success was gained over the study of Akarsu, Sanli and Arslan [22] and Duman and Sanli [23]. First of all, the effect of antenna set-up errors were clearly seen on all three components (c.f. the majority of red solid circles and plus signs over the blue ones). 
Velocity estimation was further degraded when antenna set up errors were introduced to GPS baseline components. Secondly, the success rate of the vertical component showed about $85 \%$ improvement over the study of Duman and Sanli [23].

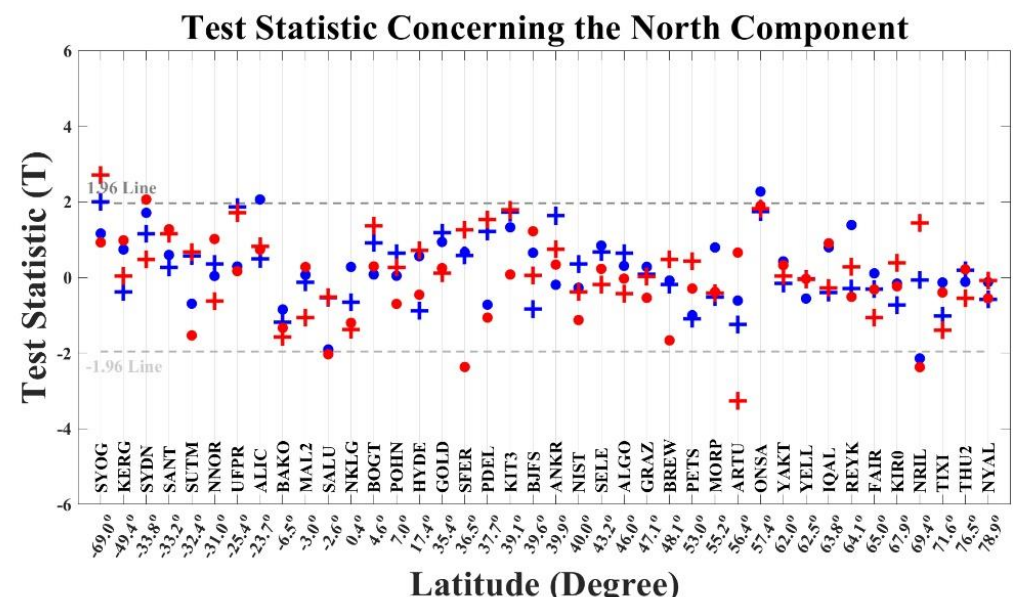

Test Statistic Concerning the East Component

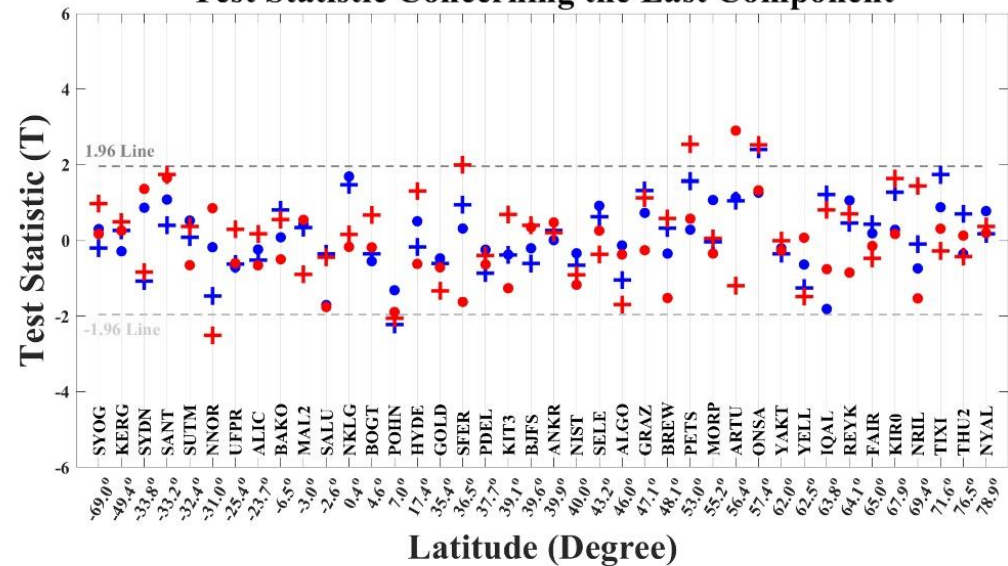

Test Statistic Concerning the Up Component

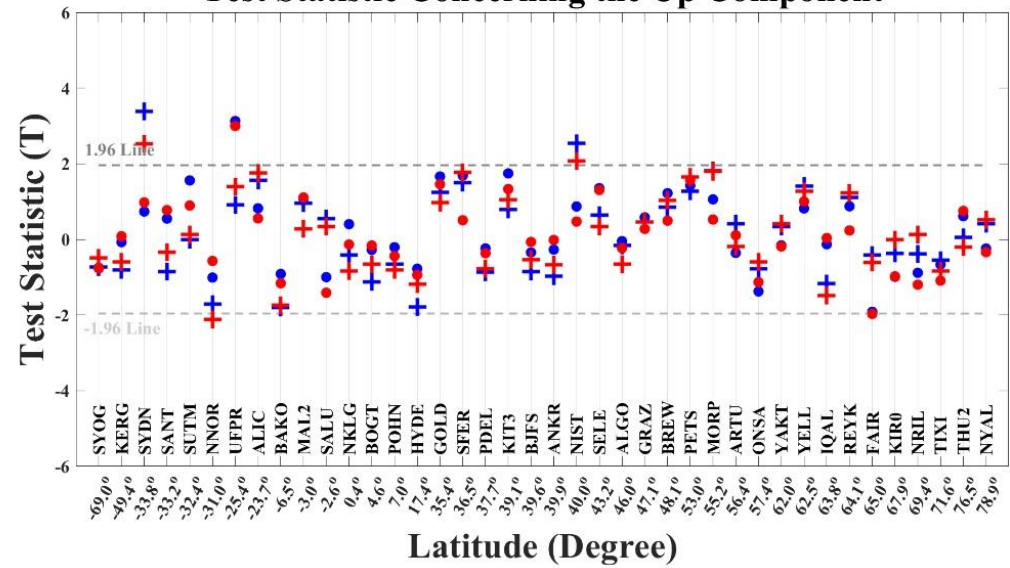

$\begin{array}{ll}-- & \text { Upper critical value for t-test results }=1.96 \\ -- & \text { Lower critical value for t-test results }=-1.96 \\ - & \text { Monthly results for four years } \\ +\quad \text { Four monthly results for four years } \\ +\quad \text { Monthly results with antenna error for four years } \\ +\quad \text { Four monthly results with antenna error for four years }\end{array}$

Figure 5. Test statistics concerning the components distributed to latitude. 
Extending the observation session from $8-10 \mathrm{~h}$ to $24 \mathrm{~h}$ significantly improved the vertical deformation rates estimated. The velocity estimation for the north and east components was also improved by about 25-40\%. Comparisons can also be made between monthly and four-monthly results. Antenna set-up biased results of four-monthly solutions gave about $8 \%$ coarser results than the antenna set-up biased one-monthly results.

One other detail that we noticed in Figure 5 was that the north component had three blue solid circles, which means some of the estimated velocities significantly differed from the truth without taking into consideration antenna set-up errors. These were the stations ALIC, ONSA, and NRIL. The same applies to the up component in that the velocity estimated at the station UFPR significantly differed from the truth. At this stage, we referred to the site specific information released by the IGS (Figure 6) and some geological reports to interpret this unexpected positioning differences. The top left figure illustrates the environment of the station ALIC. The station was installed on a bedrock, which is the standard for monitoring the tectonic motion. Multipath level and cycle slip level were very low. However it is noted in the figure that the station was surrounded by trees. The fact that the velocity estimated at ALIC significantly differed from the truth might be ascribed to signal attenuation due to tree leaves, and this deteriorates the positioning [30].

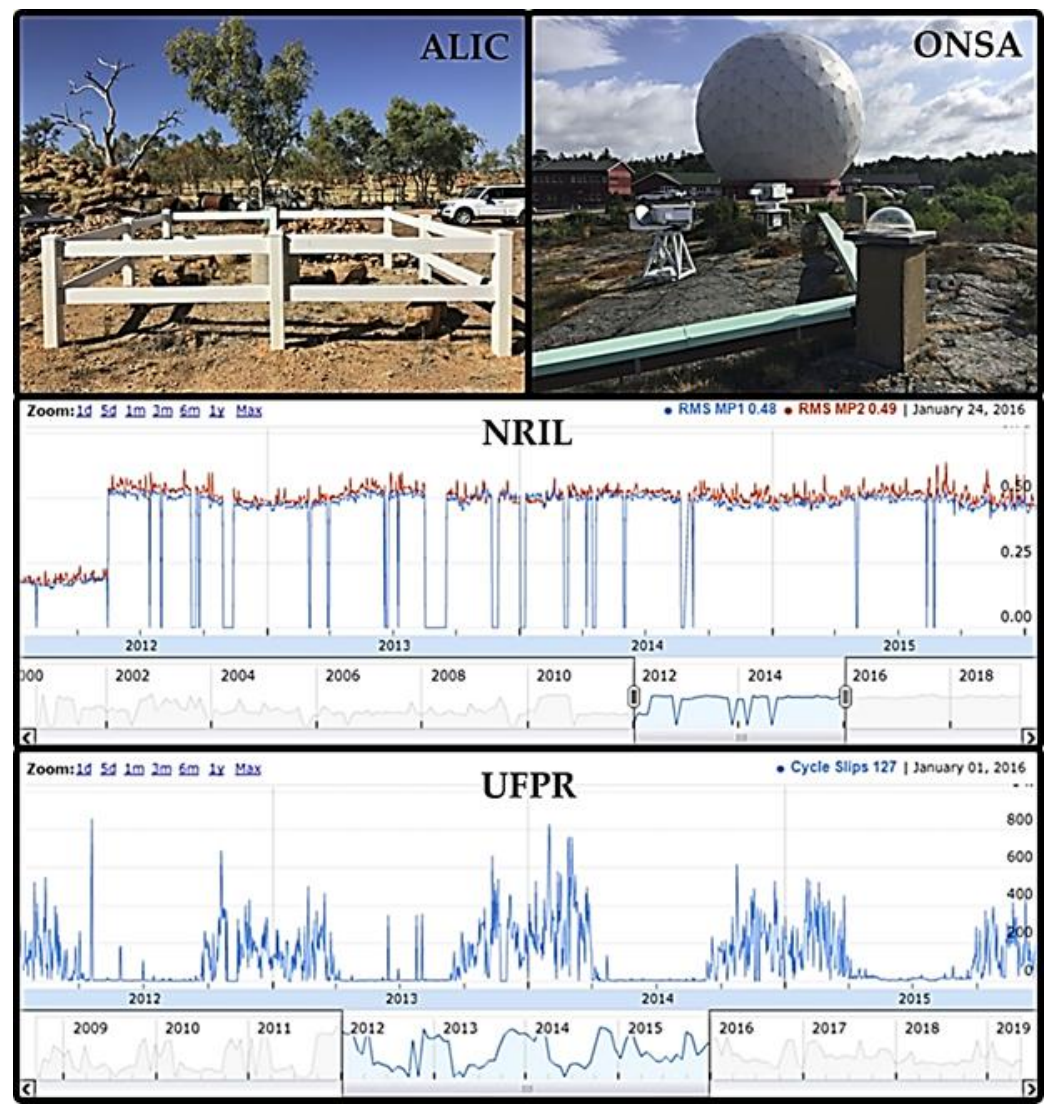

Figure 6. Site specific impressions on the IGS stations ALIC, ONSA, NRIL, and UFPR [29].

The top right figure of Figure 6 gives the environment of ONSA. ONSA was established on a bedrock. However it was placed at a space laboratory in which data were collected from other geodetic instrumentation such as VLBI antennas, gravimeter, and tide-gauges. Note the radome of a huge radio-telescope behind the GPS antenna in the figure. The reason that the estimated velocity at this station significantly differed from the truth might be ascribed to the multipath environment at the vicinity of the GNSS antenna given MP1 and MP2 multipath levels were about 0.80 for the station. In the $\log$ file of the station was reported various events in regard to the low data quality, multipath 
reduction, and equipment repairs between the years 2012 and 2016, which corresponds to our data analysis period here.

In the middle part of Figure 6 is represented the multipath quality of the station NRIL. NRIL was located on top of the roof of the seismology building as stated in the log file released by the IGS. Bukchin, et al. [31] states the station is in a tectonically stable place. The tectonic interaction between Pamir and Tien Shan was examined taking NRIL as one of the stable Eurasian reference stations in the GNSS analysis [32]. However, the multipath environment on the roof as well as shaking of the building might have degraded the positioning quality, given MP1 0.48 and MP2 0.49 multipath levels were comparatively higher. Unfortunately, a picture giving the site description of the GNSS station NRIL was not available on the internet.

Salamuni, et al. [33] states that the place where UFPR was installed is in a tectonically active region. Erosions and normal faulting are encountered in the region. Furthermore, a tremendous number of cycle slips occurred during the data collection period 2012 through 2016. See the bottom part of Figure 6 for this. High tectonic and cycle slipping activity might have caused the deterioration in the vertical positioning quality of UFPR.

\section{Conclusions}

From a global network of IGS stations, we carried out an experiment in which the ground deformation rate (i.e., velocity) due to tectonic motion estimated from campaign measurements was compared with the ground deformation rate obtained from continuous GPS data. Continuous GPS time series constructed for the IGS stations by NASA JPL were utilized in the analysis. Campaign GPS time series were generated by decimating the four-year continuous positioning solutions into monthly and four monthly samples. Learning lessons from the success of GPS campaigns performed with 8-12 $\mathrm{h}$ in the literature, we extended the duration of measurements to a full $24 \mathrm{~h}$. In other words, synthetic campaigns from continuous data were generated using solutions from $24 \mathrm{~h}$ data. Previously it was found that determining tectonic motion from a traditional 8-12 h GPS campaigns was not comparable to the one produced from GPS campaigns using $24 \mathrm{~h}$ data. With a careful refinement procedure, on the average only $50-70 \%$ of the velocities estimated for horizontal components were usable. Only $10 \%$ of the velocities produced from the vertical component of 8-12 $\mathrm{h}$ campaigns was comparable to the one produced from $24 \mathrm{~h}$ campaigns. These assessments were produced with $95 \%$ confidence level and considering a full 15-year time series. Here, we synthetically applied two different sampling from the continuous data; one measurement per month and one measurement per four months. Considering practical concerns we used four-year time series, which is a minimum data requirement for reliable deformation monitoring.

In addition, in this phase of the work, we took into account antenna tripod set up errors on positioning. Note that the data sampled from continuous IGS stations neglected the antenna set up errors. Referring to the literature for the magnitude of the antenna error, GPS campaign measurements were synthetically biased. As expected, in general, the deformation rate obtained from GPS campaigns performed once per month agreed better with the deformation rate produced from continuous GPS. However, repeating GPS campaigns once every month would be cumbersome to many operators in the field. Here, the success of horizontal positioning accuracy by campaign measurements using observations once every four months had been improved by about $25-40 \%$ whilst the success of the vertical positioning had been improved by about $85 \%$ compared to previous studies. Extending the observation duration from $8 \mathrm{~h}$ to $24 \mathrm{~h}$ played the key role in gaining this.

Note that the assessments made here were only for the determination of tectonic motion. The 1-sigma velocity estimation error of the campaign data was a factor of 5-10 coarser than those of the continuous data. The conclusions made here obviously would not apply to the monitoring of, say a fault creep requiring much more attention. For the assessment of GNSS stations in tectonically active regions, the reader should refer to site specific reports of the IGS and geological assessment of the region for better interpretations. Our overall conclusion is that the field operator is now very near to the 
$95 \%$ confidence level in monitoring of the tectonic motion especially for the north and up components if the observation session is extended to $24 \mathrm{~h}$ and campaigns are repeated every four months.

Author Contributions: D.U.S. developed the methodology. D.U.S. and Y.T. wrote the software. D.U.S. made the validations. Y.T. performed the formal analysis. D.U.S and Y.T. carried out the investigation. Y.T. wrote the original draft. D.U.S. did the review and editing. Y.T. made the visualization. D.U.S. supervised the study.

Funding: This research received no external funding.

Acknowledgments: We are grateful to NASA - JPL for opening their GPS time series archives to worldwide research community. We are also grateful to The Generic Mapping Tools (GMT) for their open source codes. We thank to the four anonymous reviewers for their constructive comments.

Conflicts of Interest: The authors declare no conflict of interest

\section{References}

1. Roberts, C.; Rizos, C. Permanent Automatic GPS Deformation Monitoring Systems: A Review of System Architecture and Data Processing Strategies. In Advances in Positioning and Reference Frames, IAG Scientific Assembly Rio de Janeiro, Brazil, September 3-9, 1997; Brunner, F.K., Ed.; Springer: Heidelberg, Berlin, Germany, 1997; Volume 118, pp. 375-380.

2. Freymueller, J.T.; Woodard, H.; Cohen, S.C.; Cross, R.; Elliott, J.; Larsen, C.F.; Hreinsdóttir, S.; Zweck, C. Active deformation processes in Alaska, based on 15 years of GPS measurements. In Active Tectonics and Seismic Potential of Alaska, Geophysical Monograph Series; Freymueller, J.T., Ed.; AGU: Washington, DC, USA, 2008; Volume 179, pp. 1-42.

3. Freymueller, J.T. Geodynamics. In Springer Handbook of Global Navigation Satellite Systems, 1st ed.; Teunissen, P.J.G., Montenbruck, O., Eds.; Springer International Publishing: Cham, Switzerland, 2017; pp. 1063-1106.

4. Blewitt, G. Advances in Global Positioning System Technology for Geodynamics Investigations. In Contributions of Space Geodesy to Geodynamics: Technology, Geodynamics Series; Smith, D.E., Turcotte, D.L., Eds.; AGU: Washington, DC, USA, 1993; Volume 25, pp. 195-213.

5. Soler, T.; Michalak, P.; Weston, N.D.; Snay, R.A.; Foote, R.H. Accuracy of OPUS solutions for 1-to 4-h observing sessions. Gps Solut. 2006, 10, 45-55. [CrossRef]

6. Hastaoglu, K.O.; Sanli, D.U. Monitoring Koyulhisar landslide using rapid static GPS: A strategy to remove biases from vertical velocities. Nat. Hazards 2011, 58, 1275-1294. [CrossRef]

7. Sanli, D.U.; Blewitt, G. Geocentric sea level trend using GPS and > 100-year tide gauge record on a postglacial rebound nodal line. J. Geophys. Res. Sol. Earth 2001, 106, 713-719. [CrossRef]

8. Kuczynska-Siehien, J.; Lyszkowicz, A.; Stepniak, K.; Krukowska, M. Determination of geopotential value W-0(L) at Polish tide gauges from GNSS data and geoid model. Acta Geod Geophys 2017, 52, 527-534. [CrossRef]

9. Tatar, O.; Poyraz, F.; Gursoy, H.; Cakir, Z.; Ergintav, S.; Akpinar, Z.; Kocbulut, F.; Sezen, F.; Turk, T.; Hastaoglu, K.O.; et al. Crustal deformation and kinematics of the Eastern Part of the North Anatolian Fault Zone (Turkey) from GPS measurements. Tectonophysics 2012, 518, 55-62. [CrossRef]

10. Muller, M.D.; Geiger, A.; Kahle, H.G.; Veis, G.; Billiris, H.; Paradissis, D.; Felekis, S. Velocity and deformation fields in the North Aegean domain, Greece, and implications for fault kinematics, derived from GPS data 1993-2009. Tectonophysics 2013, 597, 34-49. [CrossRef]

11. Aktug, B.; Dogru, A.; Ozener, H.; Peyret, M. Slip rates and locking depth variation along central and easternmost segments of North Anatolian Fault. Geophys J. Int. 2015, 202, 2133-2149. [CrossRef]

12. Wang, G.Q.; Kearns, T.J.; Yu, J.B.; Saenz, G. A stable reference frame for landslide monitoring using GPS in the Puerto Rico and Virgin Islands region. Landslides 2014, 11, 119-129. [CrossRef]

13. Hastaoglu, K.O.; Poyraz, F.; Turk, T.; Yılmaz, I.; Kocbulut, F.; Demirel, M.; Sanli, U.; Duman, H.; Sanli, F.B. Investigation of the success of monitoring slow motion landslides using Persistent Scatterer Interferometry and GNSS methods. Surv. Rev. 2017, 50, 475-486. [CrossRef]

14. Wirz, V.; Beutel, J.; Gruber, S.; Gubler, S.; Purves, R.S. Estimating velocity from noisy GPS data for investigating the temporal variability of slope movements. Nat. Hazard. Earth Sys. 2014, 14, 2503-2520. [CrossRef] 
15. Hu, Y.X.; Cheng, L.; Wang, X. Quality analysis of the campaign GPS stations observation in Northeast and North China. Geod. Geodyn. 2016, 7, 87-94. [CrossRef]

16. Liu, L.; Larson, K.M. Decadal changes of surface elevation over permafrost area estimated using reflected GPS signals. Cryosphere 2018, 12, 477-489. [CrossRef]

17. Blewitt, G.; Lavallee, D. Effect of annual signals on geodetic velocity. J. Geophys. Res. 2002, 107, ETG 9-1-ETG 9-11. [CrossRef]

18. Williams, S.D.P. The effect of coloured noise on the uncertainties of rates estimated from geodetic time series. J. Geod. 2003, 76, 483-494. [CrossRef]

19. Amiri-Simkooei, A.R.; Tiberius, C.C.J.M.; Teunissen, P.J.G. Assessment of noise in GPS coordinate time series: Methodology and results. J. Geophys. Res. 2017, 112, B7. [CrossRef]

20. Bogusz, J.; Klos, A. On the significance of periodic signals in noise analysis of GPS station coordinates time series. Gps Solut 2016, 20, 655-664. [CrossRef]

21. Hastaoglu, K.O.; Sanli, D.U. Accuracy of GPS Rapid Static Positioning: Application to Koyulhisar Landslide, Central Turkey. Surv. Rev. 2011, 43, 226-240. [CrossRef]

22. Akarsu, V.; Sanli, D.U.; Arslan, E. Accuracy of velocities from repeated GPS measurements. Nat. Hazards Earth Syst. Sci. 2015, 15, 875-884. [CrossRef]

23. Duman, H.; Sanli, D.U. Assessment of geodetic velocities using GPS campaign measurements over long baseline lengths. Nat. Hazards Earth Syst. Sci. 2019, 19, 571-582. [CrossRef]

24. Geng, J.H.; Meng, X.L.; Dodson, A.H.; Teferle, F.N. Integer ambiguity resolution in precise point positioning: Method comparison. J. Geod. 2010, 84, 569-581. [CrossRef]

25. Wang, G.Q.; Turco, M.; Soler, T.; Kearns, T.J.; Welch, J. Comparisons of OPUS and PPP Solutions for Subsidence Monitoring in the Greater Houston Area. J. Surv. Eng. 2017, 143, 05017005. [CrossRef]

26. Dixon, T.H. An Introduction to the Global Positioning System and Some Geological Applications. Rev. Geophys. 1991, 29, 249-276. [CrossRef]

27. Gili, J.A.; Corominas, J.; Rius, J. Using Global Positioning System techniques in landslide monitoring. Eng. Geol. 2000, 55, 167-192. [CrossRef]

28. Ji, K.H.; Herring, T.A. A method for detecting transient signals in GPS position time-series: Smoothing and principal component analysis. Geophys. J. Int. 2013, 193, 171-186. [CrossRef]

29. IGS. International GNSS Service. Available online: http://www.igs.org (accessed on 21 May 2019).

30. Pirti, A. Using GPS near the forest and quality control. Surv. Rev. 2005, 38, 286-298. [CrossRef]

31. Bukchin, B.G.; Mostinsky, A.Z.; Egorkin, A.A.; Levshin, A.L.; Ritzwoller, M.H. Isotropic and nonisotropic components of earthquakes and nuclear explosions on the Lop Nor test site, China. Pure Appl. Geophys. 2001, 158, 1497-1515. [CrossRef]

32. Zubovich, A.; Schone, T.; Metzger, S.; Mosienko, O.; Mukhamediev, S.; Sharshebaev, A.; Zech, C. Tectonic interaction between the Pamir and Tien Shan observed by GPS. Tectonics 2016, 35, 283-292. [CrossRef]

33. Salamuni, E.; Ebert, H.D.; Borges, M.D.; Hasui, Y.; Costa, J.B.S.; Salamuni, R. Tectonics and Sedimentation in the Curitiba Basin, South of Brazil. J. S. Am. Earth Sci. 2003, 15, 901-910. [CrossRef]

(C) 2019 by the authors. Licensee MDPI, Basel, Switzerland. This article is an open access article distributed under the terms and conditions of the Creative Commons Attribution (CC BY) license (http://creativecommons.org/licenses/by/4.0/). 